\title{
O USO DE JOGOS DE EMPRESAS EM DIFERENTES NÍVEIS EDUCACIONAIS: INTE- GRAÇÃO, PRÁTICA E PESQUISA ENVOLVENDO ESTUDANTES DE GRADUAÇÃO E PÓS-GRADUAÇÃO EM ADMINISTRAÇÃO
}

\author{
THE USE OF BUSINESS GAMES AT DIFFERENT EDUCATIONAL LEVELS: IN- \\ TEGRATION, PRACTICE AND RESEARCH INVOLVING UNDERGRADUATE AND \\ GRADUATE MANAGEMENT STUDENTS
}

Recebido em: 03/09/2018 - Aprovado em: 14/12/2018

Avaliado pelo sistema double blind review

Editor Científico: Edson Sadao Iizuka

DOI 10.13058/raep.2019.v20n1.1290

\section{HUMBERTO REIS DOS SANTOS-SOUZA humberto.souza@ifrj.edu.br}

Instituto Federal de Educação, Ciência e Tecnologia do Rio de Janeiro

\section{MURILO ALVARENGA OLIVEIRA}

\author{
Universidade Federal Fluminense
}

\begin{abstract}
RESUMO
Embora a articulação entre ensino e pesquisa seja um preceito construtivo da universidade brasileira, nota-se um distanciamento entre a graduação com seu foco no ensino e a pós-graduação com seu foco na pesquisa. Considerando a potencialidade que os jogos de empresas apresentam para a formação gerencial, permitindo a prática (sob risco e incerteza controlados) e a pesquisa, dentro dos preceitos do Laboratório de Gestão, há que se considerar o uso dessa proposta metodológica em diferentes níveis educacionais com vistas à integração de graduandos e pós-graduandos. Sendo assim, o objetivo deste artigo é compreender, por meio dos jogos de empresas, o processo de integração entre estudantes de diferentes níveis educacionais. O estudo tem caráter qualitativo, de nível exploratório-descritivo, com base em experiências na disciplina de Gestão Empresarial Simulada em um curso de pós-graduação, de uma instituição federal, na região sul do estado do Rio de Janeiro. Durante a aplicação, os estudantes da pós-graduação foram convidados a integrarem-se aos estudantes da graduação matriculados na disciplina de Laboratório de Gestão II, do curso de graduação em Administração. Após a vivência, os dados da pesquisa foram coletados a partir de entrevista semiestruturada realizada com uma amostra de estudantes e, posteriormente, analisados por análise de conteúdo. Os resultados indicam que a integração entre pós-graduação e graduação durante a vivência gerencial permitiu a manutenção ou melhora da qualidade do aprendizado social no jogo de empresas. Indicam, também, que a articulação entre ensino e pesquisa em níveis de ensino diferentes, por meio dos jogos de empresas, pode contribuir para uma relação mais virtuosa entre graduação e pós-graduação.

Palavras-chave: jogos de empresas; integração; graduação; pós-graduação.
\end{abstract}

\begin{abstract}
Although articulation between teaching and research is a constructive precept of Brazilian universities, there is a gap between undergraduate programs, with focus on teaching, and graduate programs, with focus on research. Considering the potential of business games for managerial education, allowing practice (under controlled risk and uncertainty) and research, within the precepts of management laboratories, it is necessary to consider the use of this methodological approach at different educational levels with the aim of integrating undergraduate and graduate students. Thus, the aim of this article is to better understand the process of integrating students of different educational levels through business games. The study is qualitative and exploratorydescriptive, based on the experience of playing a business game by undergraduate students enrolled in the discipline called "Simulated Business Management" along with graduate students enrolled in the discipline called "Management Laboratory II" at a federal university in the southern region of the state of Rio de Janeiro. The data were collected through semi-structured interviews and were submitted to content analysis. The results indicated that the integration between graduate and undergraduate students during the managerial experience led to maintenance or improvement of the quality of social learning through the business game. They also indicated that the articulation between teaching and research at different levels of education, through business games, can contribute to more virtuous relationship between undergraduate and graduate education.

Keywords: business games; integration; undergraduate; graduate.
\end{abstract}




\section{INTRODUÇÃO}

Novos métodos de ensino que contribuam para a formação de profissionais de gestão impingem a necessidade de inovação no ambiente educacional, uma vez que, o modelo convencional de ensino já não corresponde às expectativas dos estudantes e do mercado, pois, mantém o processo de ensino centrado no professor. No preenchimento dessa lacuna, os jogos de empresas representam uma alternativa para a formação de alunos, porque permitem o desenvolvimento de práticas gerenciais e tomada de decisão (ROSAS; SAUAIA, 2006; CLOSS; ARAMBURU; ANTUNES; 2009; OLIVEIRA; SAUAIA, 2011; KRIZ; AUCHTER, 2016).

Nesse contínuo, um dos grandes desafios na educação gerencial, quer seja na academia, quer seja em treinamento no ambiente empresarial, é propiciar o aprendizado pleno, posto que, uma das alternativas para contornar o problema é a utilização de métodos de aprendizagem vivencial, como por exemplo, os jogos de empresas (SAUAIA, 2013; OLIVEIRA; SAUAIA, 2011). Além disso, em ampla pesquisa, Kriz e Auchter (2016) apontaram que a maioria dos estudantes pesquisados prefere métodos vivenciais de ensino se comparados a métodos convencionais e, que os efeitos da aprendizagem a longo prazo são mais evidentes em estudantes submetidos a um processo de aprendizagem vivencial.

Além disso, efetuar a transposição da teoria à prática, em um ambiente controlado, permite ao estudante a tomada de decisão sob risco e incerteza, o estabelecimento das relações de causa e efeito e o desenvolvimento de competências gerenciais em um processo de aprender por fazer. Tal interação possibilita o alcance da aprendizagem significativa, vivenciada no ciclo de Kolb (KOLB; KOLB, 2005; MOTTA; MELO; PAIXÃO, 2012).

Diante desses múltiplos contextos, a proposta do Laboratório de Gestão, que congrega jogo de empresas, simulador e pesquisa aplicada, permite ao estudante, além da vivência no jogo, o contato com o mundo da pesquisa científica (OLIVEIRA, 2009; SAIAUA, 2013; SILVA, 2015). A pesquisa é indispensável na formação do estudante, uma vez que, a articulação entre ensino, pesquisa e extensão trata-se de um preceito construtivo 
da universidade brasileira. Embora ocorram discussões significativas sobre indissociabilidade do eixo ora exposto, poucas ações efetivas, que possibilitem uma real integração entre a graduação e a pós-graduação, são visualizadas (NICOLINI, 2003; BERTERO, 2007; PINTO; MOTTER JUNIOR, 2012; RODRIGUES, 2012).

Desse modo, objetiva-se com este estudo compreender uma proposta educacional que integre diferentes níveis de ensino (graduação e pós-graduação), mediante jogos de empresas, de modo a identificar as vantagens e desvantagens no processo. Dentro desse panorama, o problema de pesquisa repousa sobre o seguinte questionamento: quais as vantagens e desvantagens na utilização de jogos de empresas para integrar estudantes da graduação e pós-graduação em administração?

Tal questionamento justifica-se pela imprescindibilidade de inovar as práticas de ensino em administração que incentivem a pesquisa e o aprender pela ação e pelo dever da universidade brasileira de resguardar a integração entre o ensino e a pesquisa. Além disso, resultados satisfatórios podem ser observados quando ocorre a promoção do intercâmbio entre estudantes de níveis diferentes para fomentar a construção coletiva do conhecimento e da pesquisa (CURY, 2004; FERNANDES et al., 2015).

Diante da justificativa, a primeira suposição do estudo aponta que a aprendizagem social pode ocorrer por meio da relação estudante-estudante, visto que, a qualidade e a intensidade dessa relação são variáveis impactantes no sucesso da aplicação do jogo (KRIZ; HENSE, 2006). A segunda suposição apoia-se nos critérios propostos por Kriz e Hense (2006) para aferir a qualidade de um modelo lógico de um jogo, apontando para dois fatores, a saber: (a) maior variedade de interações entre os participantes apresenta input para a qualidade da simulação e (b) jogadores altamente qualificados alcançam melhores resultados no jogo, no que diz respeito aos objetivos de aprendizagem, em comparação com os jogadores menos qualificados. Desse modo, acredita-se que a aprendizagem social entre estudantes da graduação e da pós-graduação e a interação entre estudantes com qualificações diferentes, impactem positivamente a qualidade do jogo e, por conseguinte, o processo de aprendizagem. 


\section{OLIVEIRA}

Desse modo, para o atingimento dos objetivos, o trabalho está organizado, a partir desta introdução, na exposição da teoria que fundamenta o artigo, seguido do método, apresentando em sequência, os dados encontrados e respectiva análise e, por fim, são tecidas as considerações finais. 


\section{FUNDAMENTAÇÃO TEÓRICA}

A base teórica deste trabalho está sustentada em três principais vertentes: primeiro, aborda-se os jogos de empresas e o Laboratório de Gestão, seguido da discussão sobre jogos de empresas e a aprendizagem social e, na sequência, trata-se da relação entre graduação e pós-graduação.

\section{JOGOS DE EMPRESAS E LABORATÓRIO DE GESTÃO}

Os jogos de empresas ou business games têm sido utilizados pelas academias da área de gestão para o desenvolvimento de competências em seus estudantes (FARIA et al., 2009). Um jogo de empresas pode ser definido como um ambiente vivencial simulado com suficiente similitude com o mundo real, capaz de induzir respostas que seriam aplicadas à realidade. Caracteriza-se, também, como um método utilizado para criar ambientes vivenciais, nos quais, mudanças de comportamento e no aprendizado podem ocorrer e o comportamento gerencial pode ser observado. Nesse sentido, existem jogos de alta complexidade, que integram todas as áreas administrativas e, também, jogos mais simplificados ou funcionais, dedicados às áreas mais específicas das organizações (KEYS; WOLFE, 1990; FARIA et al., 2009).

Um dos pilares teóricos que sustentam o uso de jogos de empresas para a educação gerencial é a Teoria da Aprendizagem Vivencial - ELT (do inglês Experiential Learning Theory) de David A. Kolb (OLIVEIRA, 2009; BEN-ZVI, 2010; OLIVEIRA; SAUAIA, 2011). A ELT foi fortemente influenciada por grandes teóricos da aprendizagem e do desenvolvimento humano, tais como Paulo Freire, Carl Jung, Jean Piaget, Lev Vygotsky, John Dewey, Kurt Lewin, William James, Carl Rogers e Mary Parker Follett na busca de desenvolver uma teoria em que a experiência tenha um papel central (KOLB, 2015).

A ELT retrata, em um primeiro aspecto, a relação dialética entre a experiência concreta e a concepção abstrata, que propicia a aquisição da experiência. Em um segundo aspecto, existe, também, uma relação dialética para transformar a experiência por meio da observação reflexiva e da ex- 


\section{OLIVEIRA}

perimentação ativa. O modelo gera um processo recursivo e espiral, de tal modo que, o aprendiz toca todos os aspectos citados: experiência concreta - observação reflexiva - concepção abstrata - experimentação ativa. Dentro do contexto de aprendizagem, a ELT proporciona um processo de construção do conhecimento no qual o estudante experimenta, reflete, pensa e age, em um ciclo, experiências concretas servem de base para observar e refletir e, a partir das reflexões, é possível extrair conceitos abstratos que podem ser implicados para ação. O agir ocorre quando essa implicação é testada, o que viabiliza a criação de novas experiências, ocasionado um ciclo contínuo de aprendizagem (KEYS; WOLF, 1990; KOLB; KOLB, 2005; OLIVEIRA, 2009; OLIVEIRA; SAUAIA, 2011; HAUGE et al., 2013; SILVA; OLIVEIRA; MOTTA, 2013; KOLB, 2015). Nesse contexto, o Ciclo de Kolb pode ser visualizado na Figura 1.

Figura 1 Ciclo de Kolb

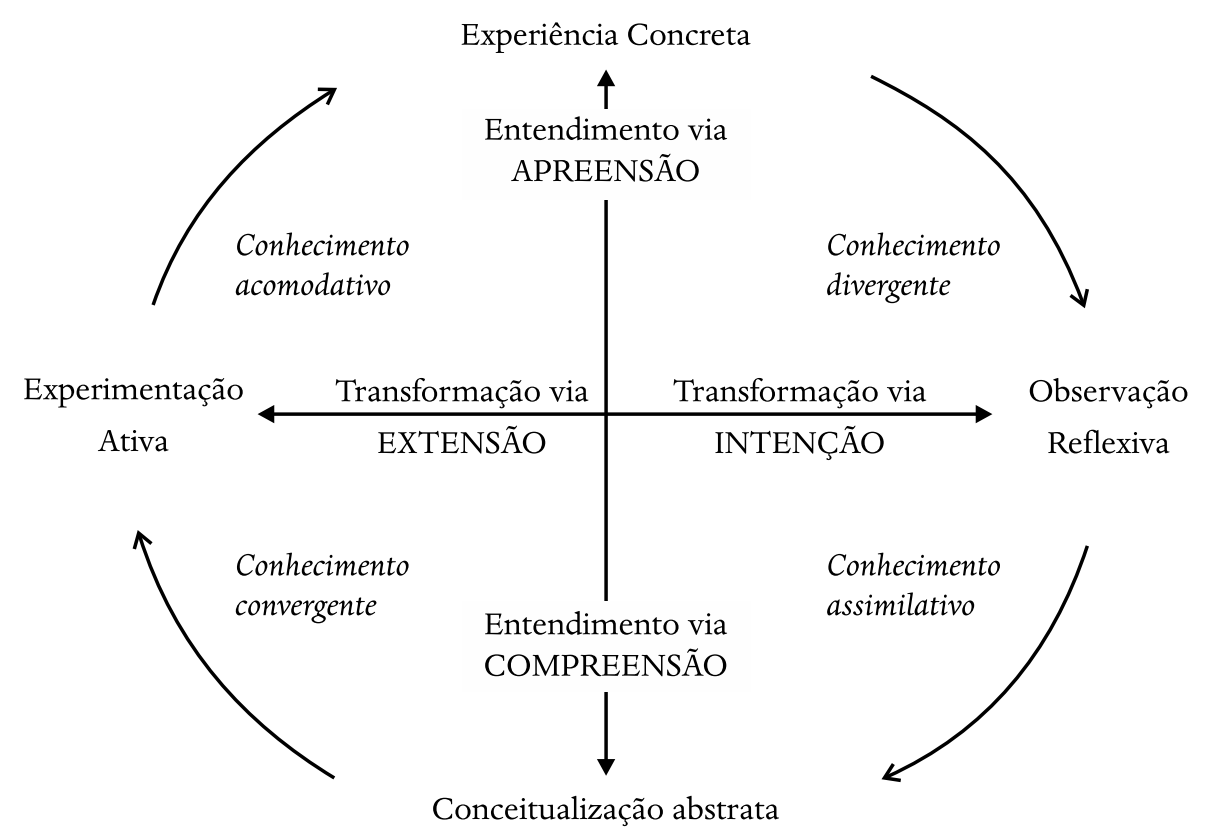

Fonte: adaptado de Kolb (2015, p.68). 
Assim, os jogos de empresas para a educação gerencial vêm preencher uma lacuna na dinâmica convencional da aprendizagem, cujo foco está no professor e não no estudante, permitindo a ligação entre teoria e prática e, por conseguinte, a demonstração da real utilidade da teoria. Nessa mesma lógica, o uso dos jogos de empresas para a educação gerencial têm sido apoiado pela literatura (KOLB; KOLB, 2005; KRIZ; HENSE, 2006; FARIA et al., 2009; BEN-ZVI, 2010; CROOKALL, 2010; STATION; JOHNSON; BORODZICZ, 2010; OLIVEIRA; SAUAIA, 2011; MOTTA; MELO; PAIXÃO, 2012; HAUGE et al., 2013; SILVA; OLIVEIRA; MOTTA, 2013; KRIZ; AUCHTER, 2016; MRTVI et al., 2017; HERNÁNDEZ-LARA; PERERA-LLUNA; SERRADELL-LÓPEZ, 2018).

Nacionalmente, destaca-se o trabalho do professor Antônio Carlos Aldair Sauaia, (OLIVEIRA, 2009; OLIVEIRA et al., 2010; MOTTA, et al. 2011; MRTVI et al., 2017) ao desenvolver a proposta metodológica do Laboratório de Gestão. A referida proposta fornece um ambiente de ensino-aprendizagem e pesquisa para que o estudante possa compreender a aplicação dos fundamentos de gestão em circunstâncias controladas, sendo, esta última, uma das vantagens da utilização de jogos em empresas para a educação gerencial, uma vez que, o desacerto do estudante não ocasionará danos irreparáveis em uma empresa real por ocasião da tomada de decisão. Assim, o Laboratório de Gestão repousa sobre o tripé conceitual que contempla o simulador organizacional, o jogo de empresas e a pesquisa aplicada (OLIVEIRA; SAUAIA, 2011; SAUAIA, 2013). Cabe destacar, o simulador é diferente de jogo, pois, o simulador é o artefato pelo qual o jogo é operacionalizado. Por sua vez, o jogo é a atividade vivencial que proporciona a tomada de decisão sob incerteza e risco, a interação entre os participantes, a construção das relações entre teoria e prática, dentre outros (ROSAS; SAUAIA, 2006; SAUAIA, 2013). Ressalva-se, ainda, que jogos de empresas apresentam grandes vantagens quando comparados aos modelos convencionais, no entanto, a proposta não substitui as aulas conhecidas como expositivas, mas, tem a potencialidade de complementá-las (SILVA; OLIVEIRA; MOTTA, 2013). 


\section{A APRENDIZAGEM SOCIAL E JOGOS DE EMPRESAS}

Ao desenvolverem um modelo lógico para aferir a qualidade de um jogo de empresas, Kriz e Hense (2006) apresentam um amplo estudo com alguns quesitos, que devem estar contidos em um jogo, para que o mesmo apresente qualidade e, consequentemente, os efeitos de aprendizagem esperados. Dentre os cinquenta parâmetros estabelecidos pelo estudo, por limitações metodológicas, abordam-se brevemente dois deles: o atingimento dos objetivos de aprendizagem e a aprendizagem social.

$\mathrm{O}$ atingimento dos objetivos educacionais é fator chave para o desenvolvimento do conhecimento por parte do estudante, a ponto da Taxonomia Revisada de Bloom apresentar um contínuo de objetivos para aprendizagem, que passa pelos mais elementares aos mais elaborados, permitindo ao estudante correlacionar os objetivos elementares já internalizados, para o atingimento de objetivos mais complexos (HAUGE et al., 2013).

Embora a interação entre os participantes seja uma variável clássica na aplicação dos jogos de empresas, há indícios de que a aprendizagem social, que ocorre por meio da relação estudante-estudante, é um fator de destaque, posto que, a qualidade e a intensidade dessa relação são variáveis impactantes no sucesso da aplicação da vivência gerencial. Ainda, o planejamento da maneira como essas interações ocorrem e como influenciam no andamento do jogo, podem ser desenhadas durante a construção do modelo lógico da simulação. Nesse sentido, cabe ressaltar que a variedade de interações entre os participantes do jogo está associada à aprendizagem social (KRIZ; HENSE, 2006). Desse modo, nota-se que a interação e a colaboração em um jogo de empresas podem estar atreladas a resultados positivos em termos de aprendizagem (LODDERS, 2013; HERNÁNDEZ-LARA; PERERA-LLUNA; SERRADELL-LÓPEZ, 2018).

As vantagens da aprendizagem cooperativa são perceptíveis no desenvolvimento do conhecimento em grupo, na disponibilidade de modelos cognitivos, bem como no conflito cognitivo, resultado da interação social. Dessa perspectiva, a construção social do conhecimento é instrumento na ativação de processos cognitivos individuais que são importantes para compreender, memorizar e transferir novos conhecimentos. 
Os processos relacionados à aprendizagem em grupo podem ser assim relacionados: identificação de lacunas no conhecimento individual e coletivo, o aumento do conhecimento compartilhado, o desenvolvimento de habilidades e de meta-conhecimento sobre determinado assunto, o desenvolvimento de habilidades sociais e a coesão motivacional e emocional dentro do grupo, bem como, a integração de conhecimento tácito (FRIEDRICH; HRON; HESSE, 2001; DOLINSKA, 2017; LE PAGE; PERROTTON, 2018).

Em outro panorama, a teoria da aprendizagem social, desenvolvida por Albert Brandura, "destaca a aprendizagem via experiência, observação e imitação, também percebe a aprendizagem como um processo desenvolvido na interação social, de forma que as ações das pessoas são também influenciadas por estímulos de seu ambiente social” (BRANDURA, 1986, apud FREITAS; GODOI, 2008, p. 45). Nesse sentido, a aprendizagem social ocorre como resultado da interação social ou envolvendo algum tipo de interação social, uma vez que, as pessoas respondem ao ambiente. A partir dessas influências, a construção do conhecimento passa por imbricações entre a motivação cognitiva e a motivação afetiva, resultando assim em uma construção pautada no social (LEFRANÇOIS, 2016).

Com base na busca pelo equilíbrio ou pelo restabelecimento dele, o indivíduo passa a construir o conhecimento por meio do outro, pois, o conhecimento, em seu processo de aquisição, só adquire sentido quando comunicado e compartilhado, isso posto, observa-se que a aprendizagem social encontra no outro, sua coluna principal, seja na observação, interação ou experimentação (GODOI; FREITAS; CARVALHO, 2011). Observa-se que, tanto para Kolb, quanto para Brandura, a aprendizagem precisa ser experimentada. Para este último, a ênfase do processo de aprendizagem está na observação e, por conseguinte, na imitação, isso porque, a observação de um evento modelado (pelo professor ou outro ator) pode culminar em algum tipo de desempenho por parte do observador (LOPES et al., 2013; LEFRANÇOIS, 2016).

Diante desses múltiplos contextos, nota-se a importância da aprendizagem social para os jogos de empresas em termos de aprendizado co- 
letivo, capacidade de inovação e desempenho das equipes (LODDERS, 2013). Entretanto, a pesquisa também é fator relevante no Laboratório de Gestão e, consequentemente, para a formação em administração. Nesse ínterim, a próxima seção aponta a integração entre graduação e pós-graduação como outro aspecto para potencializar a qualidade em ambos os níveis de ensino.

\section{INTEGRAÇÃO ENTRE GRADUAÇÃO E PÓS-GRADUAÇÃO}

A Constituição da República Federativa do Brasil, de 1988, preconiza, em seu artigo 207, o princípio da indissociabilidade entre ensino, pesquisa e extensão. A literatura que trata da integração entre graduação e pós-graduação, embora escassa, assinala que uma das estratégias para articular o ensino à pesquisa é a integração entre graduação e pós-graduação. Aponta, também, os descaminhos que o preceito constitucional sofre nas universidades brasileiras, pois, não raro, as atividades de ensino, pesquisa e extensão estão dissociadas (CURY, 2004; GOMES, 2012; RODRIGUES, 2012).

Observa-se, desse modo, a desarticulação entre graduação e pós-graduação ao se apresentarem separadas e com objetivos distintos, situadas em níveis diferentes dentro e fora da instituição de ensino (MARAFON, 2001). Esse distanciamento é justificado pela estrutura tradicional da educação superior brasileira, em que a graduação atuou como precursora da propagação dos conhecimentos que servirão de base para a atuação de futuros profissionais, enquanto a pós-graduação encarregou-se da pesquisa e da produção de conhecimento novo de maneira sistemática. De fato, a efetiva integração entre ensino e pesquisa no Brasil tem ocorrido tradicionalmente na pós-graduação stricto sensu, tendo a formação docente incluída em seu bojo (BERTERO, 2007; NUNES, 2007; RODRIGUES, 2011; VALADÃO JUNIOR; RODRIGUES, 2012).

Ainda, o desenvolvimento da pós-graduação no Brasil foi construído sob a influência de fatores endógenos das instituições, e/ou pela meritocracia, e/ou pelo foco da pesquisa desacoplada da docência, em "um crescimento paralelo entre os dois setores e cuja articulação constituída é aquela da ação de professores atuando concomitantemente na gradua- 
ção e na pós-graduação" (MARAFON, 2001, p. 120). Outro apontamento, apresentado por Cury (2004), informa que a consolidação da pós-graduação nem sempre deu-se ao mesmo tempo da consolidação da instituição, ou por outro lado, resultou do aprimoramento da graduação. Todos esses fatores elencados pela literatura, influenciaram no distanciamento entre a graduação e a pós-graduação.

O Plano Nacional da Pós-Graduação (BRASIL, 2010), delimita, como uma das estratégias para o atingimento das metas até 2020, a prática de ações voltadas à geração jovem no ensino superior com a participação da pós-graduação, pois, o desempenho da economia dependerá sobremaneira dessa geração, em virtude do envelhecimento da população e, também, com vistas ao aumento da massa crítica de pesquisa. Destaca-se, com isso, a necessidade de implementação de estratégias para a continuidade dos estudos àqueles estudantes que concluíram a graduação. Também, percebe-se a importância do pós-graduando na sociedade do futuro, espera-se que ele exerça um papel importante na economia.

Embora a pesquisa seja componente específico da pós-graduação e o ensino componente específico da graduação, ambos os níveis ora mencionados devem caminhar juntos e articulados, pois, de suas nuances, de seu vínculo planejado e das produções oriundas da integração, "a universidade poderá ganhar maior legitimidade e se beneficiar da socialização desses níveis de ensino, estendendo-os para o conjunto da sociedade" (CURY, 2004, p. 791). Nota-se, assim, que ao integrar a graduação com a pós-graduação os efeitos da interação podem ser elevados a nível macro, dado o seu potencial na produção de benefícios à sociedade.

Especificamente nos cursos de administração destaca-se o Programa de Capacitação Docente em Administração - PCDA, lançado em 2004, visava a melhoria do ensino em administração no Brasil (em consonância com o IV Plano Nacional de Pós-Graduação), de tal sorte que, tal programa contemplava projetos e atividades que miravam a integração entre graduação e pós-graduação no processo de formação docente. O esforço conjunto entre ANPAD (Associação Nacional de Pós-Graduação e Pesquisa em Administração), ANGRAD (Associação Nacional dos Cursos de Graduação 
em Administração) e CAPES (Coordenação de Aperfeiçoamento de Pessoal de Nível Superior) consolidou os editais de fomento denominados Pró-Administração, sinalizando a institucionalização e integração entre agentes no que tange a operacionalização do PCDA (FISCHER, 2005; FREITAS; FISCHER, 2007; SILVA; OLIVEIRA; MOTTA, 2013). No entanto, não há, na literatura brasileira, registros da continuidade do programa (LOURENÇO; LIMA; NARCISO, 2016).

Como exemplo de integração, destacam-se experiências exitosas da articulação entre graduação e pós-graduação, tratando-se dos programas de iniciação científica que permitem ao estudante da graduação uma experiência mais aprofundada com o mundo científico, possibilitando, também, que o estudante possa desenvolver habilidades ligadas à pesquisa (CURY, 2004; FERNANDES et al., 2015). No entanto, esse modelo é criticado, pois, alcança ou está disponível apenas a um grupo de estudantes e não à totalidade da comunidade acadêmica (MARAFON, 2001). Contudo, a literatura não se restringe somente a esse modelo.

O estudo de Fernandes et al. (2015), ao analisar os relatórios de avaliação de 35 programas de pós-graduação em enfermagem, no triênio 2007/2009, segundo dados apresentados à CAPES, identifica algumas modalidades de integração entre graduação e pós-graduação, com destaque para um programa de tutoria, no qual estudantes da graduação, inscritos em projetos de iniciação científica, receberam tutoria de estudantes do mestrado e doutorado, a ponto de haver um intercâmbio entre os projetos de iniciação científica e os projetos de dissertações e teses. O processo foi proficuo, portanto, ao viabilizar aos estudantes integrados a publicação de suas pesquisas em periódicos nacionais e internacionais.

Outro ponto de integração foi o Programa de Aperfeiçoamento de Ensino, destinado exclusivamente a pós-graduandos com vistas à habilitação para a docência. Essa intervenção foi avaliada pelos estudantes da graduação como positiva. Isso porque, a interação propiciou a revitalização de componentes curriculares e compartilhamento de experiências de trabalho dos facilitadores, contribuindo com o processo de formação e estimulando os alunos a participarem de programas de pós-graduação, dentre outros. 
Extramuros, programas que integram estudantes de níveis diferentes são oferecidos nos Estados Unidos, por exemplo, desde 1988. As experiências que um estudante da graduação deriva da integração podem influenciar positivamente na tomada de decisão de prosseguir com os estudos de pós-graduação e, ainda, melhorar o desempenho nos estudos (HATHAWAY; NAGDA; GREGERMAN, 2002; GILMORE et al., 2015). 


\section{OLIVEIRA}

\section{MÉTODO DE PESQUISA}

O presente estudo, de caráter qualitativo, consiste em uma pesquisa de nível exploratório-descritiva. Investiga, desse modo, os fatores envolvidos em uma única vivência, no intuito de aproximar-se de determinado fenômeno (o uso de jogos de empresas para a integração de estudantes de níveis diferentes), e, e procura descrever sistematicamente as principais características e comportamentos de determinado corpus de pesquisa, cujos fatores teriam nebuloso delineamento em uma pesquisa quantitativa. Em se tratando dos procedimentos técnicos, esta pesquisa caracteriza-se como ex post facto, pois, os dados foram fornecidos por pessoas diretamente envolvidas em um quase-experimento e pela não possibilidade de manipulação das variáveis, uma vez que, o fenômeno ocorreu antes da pesquisa ser realizada. Desse modo, como a disciplina que integrou estudantes de níveis diferentes em um ambiente vivencial já havia manifestado seus efeitos ao longo do tempo, restou aos pesquisadores uma investigação das relações entre os fatores envolvidos no fenômeno (SILVA; MENEZES, 2005; GIL, 2008; VERGARA, 2009; COOPER; SCHINDLER, 2011; RICHARDSON, 2012). Nesse sentido, para melhor visualização, a Figura 2 apresenta o mapa do método. 
Figura 2 Mapa da Pesquisa

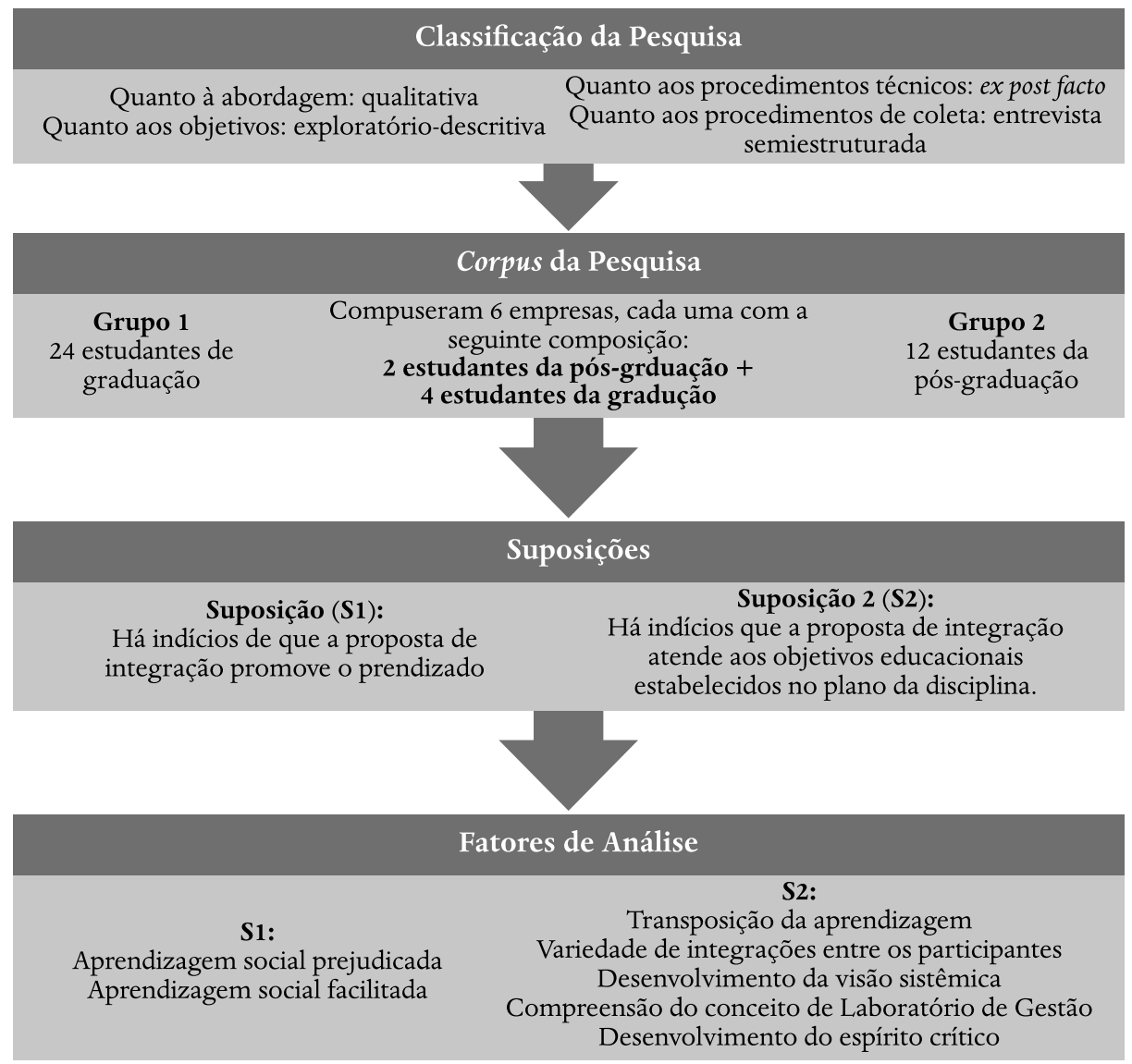

Fonte: elaborado pelos autores com base em Silva e Menezes (2005), Kriz e Hense (2006) e Vergara (2009).

Sendo assim, o estudo investigou as interações entre estudantes de níveis diferentes submetidos a um jogo de empresas, seguindo os preceitos do Laboratório de Gestão, em uma instituição federal de ensino superior (IFES), na região sul do estado do Rio de Janeiro. Dois grupos de estudantes foram integrados sendo, o primeiro grupo, composto por estudantes da graduação em administração matriculados na disciplina de Laboratório de Gestão II e, o segundo grupo, composto por estudantes matriculados na disciplina de Gestão Empresarial Simulada no curso de Mestrado Pro- 
fissional em Administração. Como resultado, seis grupos foram formados, cada grupo compunha o corpo de executivos de uma empresa simulada, composta por quatro estudantes da graduação e dois estudantes da pós-graduação.

Como instrumento para coleta de dados foi utilizada a entrevista semiestruturada. O roteiro de entrevista seguiu os preceitos apontados por Flick (2009), relativos ao não direcionamento, especificidade, espectro e profundidade. Conforme recomendado pelo mesmo autor, as entrevistas foram gravadas em equipamento eletrônico e, posteriormente, transcritas na íntegra, totalizando 26 páginas. Ressalta-se que a entrevista foi construída com base no modelo lógico de Kriz e Hense (2006) para descrever a proposta metodológica que integre alunos de níveis diferentes por meio dos jogos de empresas, de modo a identificar as vantagens e desvantagens no processo. Ao todo, foram entrevistados doze estudantes e o professor mediador responsável pela proposta, compondo, assim, o corpus de pesquisa. Por conveniência, foram escolhidos para entrevista dois estudantes de cada equipe: um estudante da pós-graduação e um estudante da graduação.

Acentua-se, ainda, que o modelo lógico proposto por Kriz e Hense (2006) foi utilizado como base teórica para construção das suposições e para os parâmetros de avaliação por ser um instrumento que permite a avaliação de jogos de empresa, em especial, quando considerados os resultados a longo prazo. Um modelo lógico objetiva indicar como o jogo, seus participantes e seu ambiente interagem e obtêm os resultados desejados. $\mathrm{O}$ modelo foi construído com base na ciência da análise que avalia os jogos de empresas a partir de seus usos para as testagens de teorias e, na ciência do design, avalia os jogos de empresas a partir da perspectiva da usabilidade do artefato (KLABBERS, 2003; 2018). Outro fator relevante para escolha desse modelo é que o mesmo foi publicado no principal periódico sobre jogos de empresas e é utilizado como framework para avaliação da aplicação dos mesmos (MAYER; WARMELINK; BEKEBREDE, 2013; KRIZ; AUCHTER, 2016).

Assim, a composição das suposições do estudo também seguiu o modelo lógico proposto por Kriz e Hense (2006) ao apontar que a interação en- 
tre os participantes é uma variável clássica na aplicação do jogo de empresa e, ao indicar que a aprendizagem social, resultante da relação estudante-estudante, é, igualmente, um fator de destaque. A qualidade e a intensidade dessa relação são variáveis impactantes no sucesso da aplicação do jogo de empresas, tornando-se, portanto, a primeira suposição do presente estudo.

Para a construção da segunda suposição, Kriz e Hense (2006) estabelecem alguns critérios para determinar a qualidade do modelo lógico de um jogo ou simulação, apresentando algumas variáveis determinantes para a qualidade do processo. Para o presente estudo, os critérios que tangenciam a pergunta de pesquisa foram os seguintes: (1) maior variedade de interações entre os participantes como input para a qualidade da simulação e (2) jogadores altamente qualificados alcançam melhores resultados no jogo (em relação aos objetivos de aprendizagem) em comparação aos jogadores menos qualificados.

Diante da segunda suposição, há que considerar os objetivos de aprendizagem das disciplinas. Desse modo, de forma resumida, o objetivo geral da disciplina de Gestão Empresarial Simulada foi apresentar a proposta do Laboratório de Gestão como metodologia para a educação gerencial, combinando jogos de empresas e pesquisa aplicada. Os objetivos específicos almejam estimular a visão sistêmica, a transposição da aprendizagem e o desenvolvimento do espírito crítico. Os objetivos propostos para os estudantes da graduação são similares, no entanto, com método substancialmente diferente (OLIVEIRA, 2017).

Realizada a coleta, a etapa seguinte consistiu-se da análise dos dados. Optou-se pela análise de conteúdo, definida como o "conjunto de técnicas de análise das comunicações visando obter, por procedimentos sistemáticos e objetivos, a descrição do conteúdo das mensagens” (BARDIN, 2013, p.42). Nesse sentido, os indicadores podem apresentar-se de forma quantitativa ou qualitativa, de modo a permitir a inferência de conhecimentos relativos ao modo de produção e recepção de cada mensagem. Para a análise de conteúdo utilizou-se a análise categorial que "funciona por operações de desmembramento do texto em unidades, em categorias segundo reagrupamentos analógicos” (BARDIN, 2013, p. 153). O método da análise de conte- 


\section{OLIVEIRA}

údo possui três fases distintas, a saber, pré-análise, exploração do material e o tratamento dos resultados, bem como, sub etapas (BARDIN, 2013).

Após a transcrição das entrevistas, utilizou-se o software ATLAS.ti ${ }^{\circledR}$ para organização e classificação do material levantado na pesquisa, em uma "operação de codificação [...] em função de regras previamente formuladas" (BARDIN, 2013, p. 101). Nesse caso, as regras formuladas seguiram critérios determinantes para a qualidade em um jogo de empresas apontados por Kriz e Hense (2006), consonantes às hipóteses do presente estudo, descritas na Figura 2. Por fim, prosseguindo com o tratamento dos dados obtidos por meio do método, os achados são analisados e apresentados na sequência. 


\section{APRESENTAÇÃO E ANÁLISES DOS DADOS}

A aplicação do jogo de empresas teve duração aproximada de dois meses, compreendendo oito rodadas de jogo. As equipes foram constituídas, em média, por dois estudantes da pós-graduação e quatro estudantes da graduação, de modo que, cada equipe constituiu uma empresa. As equipes foram classificadas como empresas atacadistas ou manufatureiras, sendo assim, três empresas atacadistas negociavam livremente com três empresas industriais, em um ambiente econômico de oligopólio. As relações com o varejo e com os fornecedores de matéria-prima eram randomizadas pelo simulador empresarial computadorizado.

Ao final de cada rodada, as empresas recebiam relatórios sobre seus respectivos desempenhos, influenciados diretamente pela tomada de decisão sob risco e incerteza, a pontuação era baseada no ROI (retorno sobre investimento). Cada estudante era responsável por uma área funcional da empresa (Planejamento, Recursos Humanos, Financeiro, Marketing, Operações e Presidência) e, ao final da disciplina, como principal componente da avaliação, os estudantes apresentavam os resultados de suas organizações, bem como, um relatório técnico ou um artigo científico com base na vivência organizacional simulada, dando à pesquisa seu espaço no aprendizado.

Segundo a entrevista com o mediador, a ideia da integração entre estudantes de níveis diferentes deriva-se de um movimento de integração na pós-graduação, pois, alguns estudantes que destacavam-se nas disciplinas de Laboratório de Gestão Simulada I e II, durante a graduação, eram convidados, pelo mediador, para cursarem a disciplina de Gestão Empresarial Simulada no mestrado, como alunos especiais ou cursando-a como optativa ainda na graduação.

No entanto, para a proposta na qual debruça-se este estudo, a motivação partiu da necessidade de criar um número suficiente de grupos que propiciasse um ambiente competitivo, assim como, da necessidade de fornecer ao aluno da pós-graduação, que porventura poderá exercer o magistério, a oportunidade de constatar como os jogos de empresas, para o ensi- 


\section{OLIVEIRA}

no gerencial, podem ser aplicados na graduação e, por fim, para atender à necessidade de volume de dados necessários em ambiente laboratorial para a pesquisa de uma participante do programa de pós-graduação orientada pelo próprio mediador.

Tabela 1 Distribuição de Frequência nas Categorias

\begin{tabular}{lcc}
\multicolumn{1}{c}{ Suposição 1 } & Freq. & $\%$ \\
\hline Aprendizagem social facilitada & 21 & 72,97 \\
\hline Aprendizagem social prejudicada & 10 & 27,03 \\
\hline Total de Observações & 31 & \\
\multicolumn{1}{c}{ Suposição 2 } & 17 & 34,70 \\
\hline Variedade de interações entre os participantes & 15 & 30,61 \\
Transposição da aprendizagem & 8 & 16,32 \\
Desenvolvimento do espírito crítico & 6 & 12,25 \\
\hline Desenvolvimento da visão sistêmica & 3 & 6,12 \\
\hline Compreensão do conceito de Laboratório de Gestão & 49 & \\
\hline Total de Observações & & \\
\hline
\end{tabular}

Fonte: dados da pesquisa.

Para melhor visualização dos resultados, a Tabela 1 apresenta a distribuição de frequência por categorias e a Figura 3 apresenta descrição mais detalhada das categorias analisadas. Dessarte, pode-se identificar a frequência dos conteúdos declarados pelos entrevistados em suas respectivas empresas, ressaltando que, tais empresas foram numeradas com algarismos de um a seis para preservar a identidade dos estudantes.

$\mathrm{Na}$ Tabela 1 estão dispostas as suposições com as categorias utilizadas no estudo. Para a Suposição 1, que trata da aprendizagem social, os entrevistados revelaram, nas declarações, que a proposta de integração entre os níveis de formação facilitou o aprendizado pelas relações entre os participantes $(72,97 \%)$. Em relação a Suposição 2, que se refere aos objetivos educacionais propostos pela disciplina, as categorias com a maior frequência foram justamente as que se associam à aprendizagem social, à 
variedade de interações com os participantes $(34,7 \%)$ e à própria transposição da aprendizagem $(30,61 \%)$; as demais categorias representam aproximadamente um terço das impressões dos entrevistados.

Esses achados coadunam-se com a teoria, uma vez que, o trabalho em equipe mediará o processo de tomada de decisão. Nesse sentido, nota-se que o estudante, ao aliar teoria e prática, precisa negociar com os demais diretores da empresa simulada para que sua sugestão, aplicação de uma técnica de gestão embasada teoricamente, possa contribuir para o sucesso da organização. Além disso, cabe ressaltar que todo o processo de decisão deve ser anuído por todos os diretores da empresa. Por outro lado, quando um estudante, mais ou menos experiente, vivencia determinada situação dentro no jogo, que tenha similaridade com o mundo real, percebe-se que existe a oportunidade do compartilhamento de experiências e de observação por parte dos outros membros da equipe que, por ventura, não tenham tido esse tipo de experiência. Em ambos os casos, os membros estão envolvidos em um conflito cognitivo e, ao mesmo tempo, na construção coletiva de soluções, em que a observação e a experimentação têm papel fundamental, o que, tanto para a ELT, quanto para a Teoria da Aprendizagem Social, representam etapas importantes para a aprendizagem (FRIEDRICH; HRON; HESSE, 2001; KOLB; KOLB, 2005; GODOI; FREITAS; CARVALHO, 2011; LOPES et al., 2013; SAUAIA, 2013; KOLB, 2015; LEFRANÇOIS, 2016; DOLINSKA, 2017).

Assim sendo, a relação entre esses fatores pode ser resumida na fala da estudante da pós-graduação da Empresa 5:

Também a gente percebe como um mestrando que, que... por a gente ter uma informação mais antecipada, a gente consegue perceber também, que coisas novas, é... pontos novos surgem, né? Que quebram um pouco os nossos paradigmas, que são atuações até versáteis né? De formas mais ágeis até que, que... chega até numa solução que a gente até previu, mas é... são soluções mais rápidas. Então achei que... com relação a isso é um ganho também né... apesar da [nossa] experiência, mas a gente não tem experiências com coisas novas e o novo ele é o futuro né? 


\section{OLIVEIRA}

A partir dessas considerações, é possível perceber que a aprendizagem social, entre estudantes de níveis diferentes, pode facilitar a aprendizagem quando os estudantes estão em busca de uma solução para um problema organizacional (DOLINSKA, 2017). Além da estudante da pós-graduação da Empresa 5, outros oito estudantes tiveram alguma percepção positiva a respeito da aprendizagem social propiciada pela vivência, a ponto de uma estudante da graduação, membro da Empresa 2, explicitar que:

A gente... da graduação, todas as três graduandas da equipe é a primeira graduação, então pra gente é assim, uma experiência muito interessante já poder ter um contato mais próximo com alguém que é professor, com alguém que já tem uma experiência maior, com alguém que já tá fazendo um mestrado, que já tem conhecimento maior, talvez até publicações na área. É realmente muito interessante, a gente aprende bastante.

Nesse sentido, Kriz e Hense (2006) classificam a interação social entre os participantes como uma variável indispensável para o processo de aplicação de jogos de empresas e, pelo relato da maioria dos estudantes, o estudo também aponta que a aprendizagem social pode ocorrer por meio da relação estudante-estudante. Assim sendo, segundo os autores, a aprendizagem social é fator relevante para a qualidade do jogo de empresas. Além desses fatores, segundo Godoi e Freitas (2008), a aprendizagem ocorre a partir da interação social, não menos impactantes, as situações e o contexto, figuram-se fundamentais para esse processo, ambos fatores elucidados neste estudo. A relação positiva no processo de integração entre pós-graduação e graduação observada aqui, embora careça de mais aprofundamento, parece coadunar com os resultados de pesquisas similares (HATHAWAY; NAGDA; GREGERMAN, 2002; CURY, 2004; FERNANDES et al., 2015; HERNÁNDEZ-LARA; PERERA-LLUNA; SERRADELL-LÓPEZ, 2018).

A primeira suposição do estudo também tangencia a aprendizagem social prejudicada. Nesse âmbito, cinco estudantes apontaram alguma dificuldade em função da integração entre graduação e pós-graduação, a exemplo disso, o estudante da graduação da Empresa 4 relata: "a gente 
percebeu que assim, os alunos do mestrado do nosso curso eram muito passivos, nos outros grupos eles tinham computadores, teve gente... membros muito mais participativos". Ademais, o estudante da pós-graduação da Empresa 4 também acrescenta:

porque os dois foram segregados do grupo, não só eu, mas como o [outro aluno da pós-graduação] também. Então é... eu queria ter integrado mais, eu poderia ter contribuído mais especialmente porque tenho uma vivência de empresa, então a minha visão é um pouco mais ampliada. E eu vou te dizer que elas perderam o meu potencial e o potencial do [outro aluno da pós-graduação] que é uma pessoa inteligentíssima.

É importante destacar que dos cinco estudantes descontentes com o processo de integração, dois pertenciam a mesma equipe, o que pode indicar um desentendimento interno no grupo, sinalizando, ainda, um fato isolado dentro da experiência. Nesse contexto, a teoria aponta que a qualidade da interação entre os participantes pode afetar o sucesso da aplicação do jogo, implicando resultados abaixo da média obtidos pelo grupo durante a vivência (KRIZ; HENSE, 2006; LODDERS, 2013). Entretanto, há indícios de que o desempenho em um jogo de empresas não possui correlação direta com a aprendizagem significativa, que, por sua vez, pode ocorrer independentemente do resultado no jogo (SAUAIA, 2006; OLIVEIRA et al., 2010; SILVA; OLIVEIRA; MOTTA, 2013).

O estudante da graduação da Empresa 2, insatisfeito com a integração, relata que a iniciativa e os conhecimentos dos alunos da pós-graduação acabaram por suprimir o protagonismo dos estudantes da graduação, ainda assim, o mesmo estudante relata pontos positivos da integração ao dizer que "as pessoas da graduação aprenderam a confiar nas pessoas do mestrado pra tomar as melhores decisões". Embora tenham reconhecido que as vantagens da integração sobrepujem as desvantagens, outros dois estudantes da pós-graduação, das Empresas 6 e 3, descrevem pontos negativos da integração com respeito a não adesão dos estudantes da graduação em determinadas estratégias sugeridas e, respectivamente, com respeito à falta de protagonismo dos estudantes da graduação. 


\section{OLIVEIRA}

Evidencia-se, especificamente nessa situação, que essa era uma limitação esperada para o processo, isso porque, a entrevista com o mediador revelou que "a expectativa de ter um aluno mais experiente, ele [estudante da graduação] poderia ficar um pouco mais tranquilo na hora de tomar as decisões... né? ... mas isso faz parte de qualquer grupo”.

Figura 3 Frequência por Categorias e Equipes

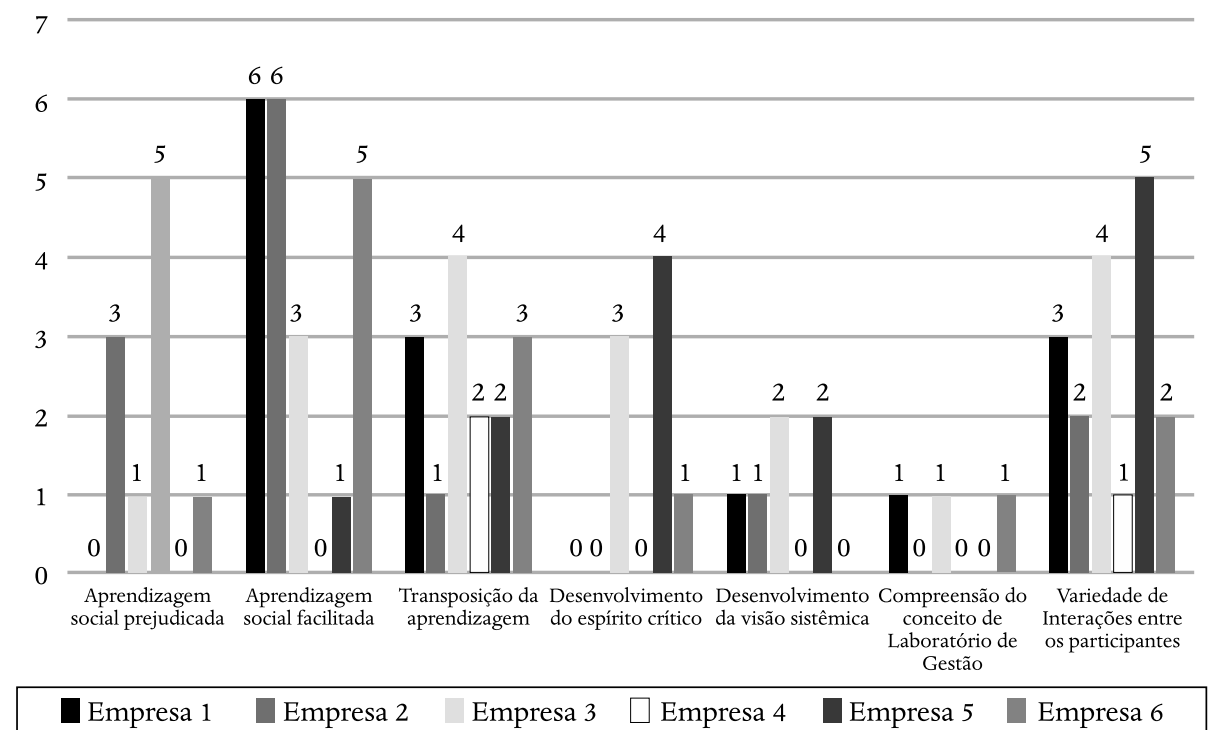

Fonte: dados da pesquisa.

Para a segunda suposição, inicialmente, analisou-se a variedade de interações entre os participantes como input para a qualidade do jogo, que, conforme abordado, está relacionada com a aprendizagem social (KRIZ; HENSE, 2006). Para essa característica, classifica-se como válidas apenas as falas que denotam algum tipo de valor para uma interação que fosse diferente da esperada para o jogo. Nesse sentido, dez estudantes (quatro alunos da graduação e seis alunos da pós-graduação) apresentaram argumentos que valorizavam uma interação com pessoas diferentes do habitual no ambiente do jogo. Dentre elas, destaca-se a fala da estudante da graduação, membro da Empresa 1: 
Foi um processo muito interessante. A gente ficou, assim, bem entusiasmado de saber que haveria essa conexão né? de chegar pessoas diferentes pra poder atuar com a gente, de saber que essa é a primeira vez que acontece né, que isso não existia antes, então assim... foi muito interessante!

Para o estudante da pós-graduação da Empresa 1, a mudança na composição dos integrantes do jogo foi benéfica: “então, essa integração entre a graduação e a pós-graduação foi válida e acho que até seria uma... uma proposta pro [mediador] dar uma avaliada pra ver se esse não poderia ser um modelo né, a ser adotado”.

Abordando os objetivos de aprendizagem da disciplina (parte da segunda suposição), a transposição da aprendizagem apresentou o maior número de apontamentos (15 ocorrências), realizados por dez estudantes, sendo cinco da graduação e cinco da pós-graduação. Todas as declarações revelam a percepção de que a teoria foi aplicada em algum momento no jogo, ou ainda, que as experiências obtidas estão sendo úteis no mundo do trabalho, revelando o aprendizado significativo (OLIVEIRA, 2009; MOTTA; MELO; PAIXÃO, 2012; HAUGE et al., 2013; KRIZ; AUCHTER, 2016). Como os estudantes do mestrado poderão ingressar na atividade docente no futuro e consonante aos objetivos de um programa de pós-graduação: formação de profissionais capacitados para o ensino, a percepção do atingimento desse objetivo educacional é relevante, pois, evidencia a necessidade de pensar a educação na graduação no sentido de contribuir para o processo de aprendizagem e não apenas contribuir no sentido da transmissão do conhecimento (BERTERO, 2007; VALADÃO JUNIOR; RODRIGUES, 2012; LOURENÇO; LIMA; NARCISO, 2016).

O desenvolvimento do espírito crítico, apontado durante o jogo enquanto objetivo de aprendizagem, foi assunto em quatro entrevistas. Dos quatro estudantes que demonstraram, em seus relatos, ter desenvolvido de alguma maneira o espírito crítico no jogo, dois estudantes pertencem à pós-graduação e dois estudantes pertencem à graduação. A reflexão da estudante da pós-graduação da Empresa 5, ilustra esse ponto: 
Esse laboratório, eu acho que a contribuição número um de ser uma prática positiva realmente é isso, esse estreitamento e também ... a ... oportunidade de você estar é tendo um olhar até pra você como estudante, é como aprendiz vamos dizer, é... quais os seus pontos deficientes que você ainda não tinha observado, então eu acho que isso é uma oportunidade legal de... de estar observando isso e, em tempo, buscar conhecimento para você ... melhor, porque as vezes você não consegue mapear alguns pontos e na prática você consegue vivenciar até mesmo as adversidades que existem no grupo.

Ainda, no que concerne aos objetivos específicos das disciplinas, cinco estudantes relataram que o jogo propiciou o desenvolvimento da visão sistêmica, habilidade de encarar a organização como um todo, a partir da recombinação dos conceitos fragmentados no ensino das teorias (OLIVEIRA, 2009; SAUAIA, 2013). Dos cinco estudantes, três pertencem a graduação e dois categorizam-se como alunos da pós-graduação. Uma das percepções de destaque é a de um estudante da graduação que se refere ao Laboratório de Gestão como "um momento que você vivencia, é... aspectos gerais de uma empresa de uma forma macro".

Por fim, o objetivo geral das disciplinas foi apresentar a proposta do Laboratório de Gestão como método para a educação gerencial, combinando jogos de empresas e pesquisa aplicada (OLIVEIRA, 2017). Nesse sentido, apenas três estudantes da pós-graduação tiveram suas respostas classificadas dentro desse escopo, categoria essa, com menos respostas classificadas em todo o estudo.

Quanto aos objetivos de aprendizagem, a teoria estabelece que jogadores altamente qualificados alcançam melhores resultados no jogo no comparativo com os jogadores que possuem menos qualificação (KRIZ; HENSE, 2006). Nessa perspectiva e com base nas categorizações das entrevistas, os estudantes da pós-graduação tiveram maior taxa de resposta aos objetivos educacionais, se comparados aos estudantes da graduação, com destaque à compreensão do conceito de Laboratório de Gestão, designado corretamente apenas pelos estudantes da pós-graduação. Fator relevante, por indicar que os estudantes do mestrado, ao possuírem mais horas de 
estudo e qualificação, podem ser vetores da aprendizagem quando integrados à graduação (FERNANDES et al., 2015).

Figura 4 - Mapa de Relações Entre os Fatores de Análise

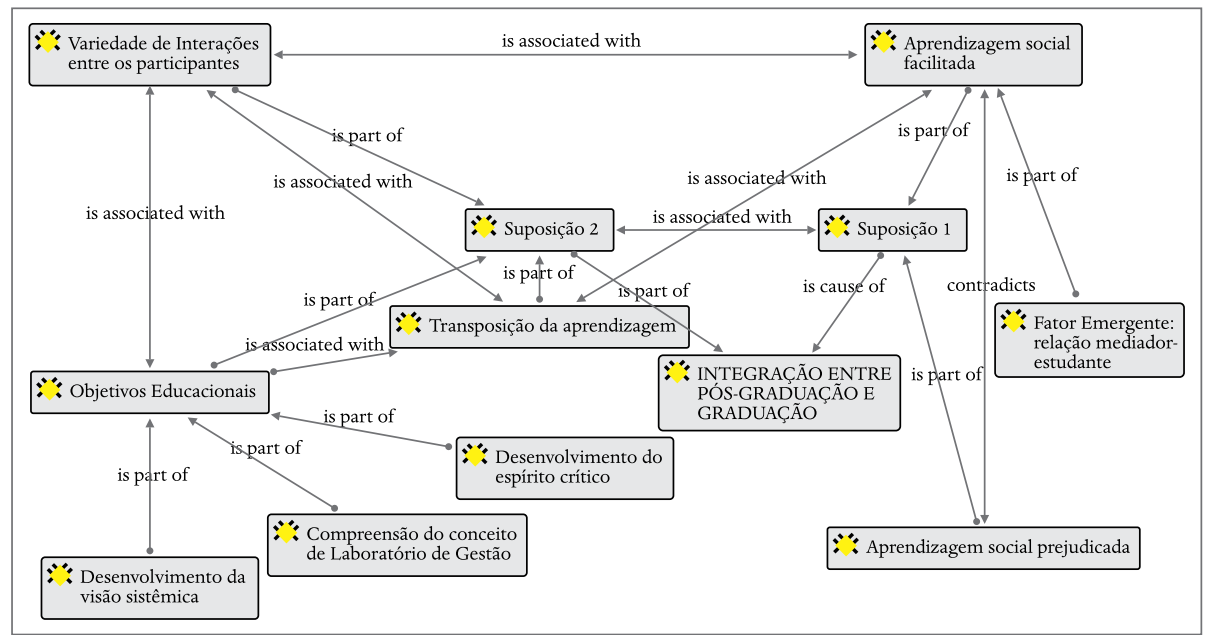

Fonte: dados da pesquisa.

Emergiram da análise das entrevistas considerações positivas sobre o fator relativo à qualidade da relação estudante-mediador, no tocante ao suporte e à instrução. Embora não delimitados nas categorias de análise, a dimensão do processo desenhada no modelo lógico de Kriz e Hense (2006), abarca a relação estudante-mediador, como sendo uma variável crítica para o sucesso de jogo. Por fim, a análise de conteúdo realizada, por meio do software ATLAS.ti ${ }^{\circ}$, gerou um mapa que facilita a visualização das relações entre os fatores de análise apresentado na Figura 4. 


\section{CONSIDERAÇÕES FINAIS}

Diante do problema de pesquisa: vantagens e desvantagens na utilização de jogos de empresas para integrar estudantes da graduação e pós-graduação em administração, pôde-se observar, como vantagens, que os aspectos centrais da vivência coadunam-se, em linhas gerais, com a teoria à luz do modelo lógico de Kriz e Hense (2006), indicando que a qualidade figura-se interiorizada na vivência gerencial e, consequentemente, no processo integração e aprendizagem em estudo. Outro fator de destaque, é o fomento à pesquisa proporcionado pela vivência, que se apresenta tão necessário à academia brasileira, pois, um dos pressupostos do Laboratório de Gestão é a pesquisa aplicada (CURY, 2004; OLIVEIRA, 2009; OLIVEIRA; SAUAIA, 2011; RODRIGUES, 2012; FERNANDES et al., 2015).

Ademais, pôde-se observar indícios de que a aprendizagem social constitui-se fator essencial para a vivência, propiciando maior variedade de interações entre os participantes., O processo de transposição da teoria à prática foi facilitado pela maior amplitude das experiências do corpo de estudantes. Em linhas gerais, os objetivos de aprendizagem foram melhor alcançados pelos estudantes com mais qualificação, o que indica que os estudantes de pós-graduação podem ser vetores da aprendizagem durante um processo de integração. Nesse seguimento, as duas suposições do estudo foram confirmadas, uma vez que, a aprendizagem social entre estudantes da graduação e da pós-graduação e a interação entre estudantes com qualificações diferentes impactaram positivamente na qualidade do jogo e, por conseguinte, no processo de aprendizagem (KRIZ; HENSE, 2006).

Como desvantagens, parece haver indícios de que a experiência de integração não mostrou-se satisfatória para dois estudantes, no entanto, esses estudantes pertenciam a mesma equipe/empresa e, as entrevistas de ambos, indicam uma segregação no grupo. Isso nos leva a supor que houve problemas de coesão (fenômeno que pode ocorrer em qualquer grupo de pessoas), o que pode ter prejudicado o grupo, posto que, os resultados econômicos da equipe, durante o jogo, não foram satisfatórios. Desse contexto, pode-se notar que uma equipe em que a integração é prejudicada, seja 
por falta de coesão ou por algum tipo de desentendimento, a ocorrência da aprendizagem social também é dificultada e, consequentemente, os resultados, em termos de desempenho, podem não ser totalmente satisfatórios. Ainda assim, para esse caso, os resultados no jogo devem ser considerados com parcimônia, pois, o desempenho no jogo não está diretamente atrelado à aprendizagem significativa (SAUAIA, 2006; OLIVEIRA et al., 2010; SILVA; OLIVEIRA; MOTTA, 2013).

Ainda, tratando das desvantagens da integração, outros três estudantes, que apontaram algum tipo de insatisfação, relataram pontos positivos para a aprendizagem social, para eles, as vantagens superam as desvantagens. Esses achados permitiram atingir o objetivo da pesquisa que tangenciava a compreensão uma proposta educacional que integrasse diferentes níveis de ensino (graduação e pós-graduação) por meio dos jogos de empresas, de modo a identificar as vantagens e desvantagens no processo.

As contribuições do estudo abarcam o papel da aprendizagem social em um jogo de empresas na implementação de uma maior variedade de interações entre os participantes que, por sua vez, pode ter facilitado a transposição da aprendizagem. Tangencia, também, os aspectos relativos aos benefícios da integração de estudantes em níveis diferentes em administração, com foco na prática gerencial e na pesquisa. Embora o estudo não permita concluir que a integração influencie o estudante da graduação no ingresso para a pós-graduação, há indícios de que a experiência pôde propiciar aos graduandos algumas percepções sobre o funcionamento da pós-graduação, bem como, suas potencialidades e desafios, diminuindo a distância existente entre os dois níveis. Ainda assim, o estudo contribui para o escasso debate sobre a integração entre graduação e pós-graduação em administração ao avançar e discutir esse processo sob o prisma dos jogos de empresas.

Resultado das limitações, salienta-se que o estudo tratou apenas de uma única experiência, o que impossibilita generalizações. Além disso, nem todos os estudantes foram entrevistados. Em termos proporcionais, $50 \%$ dos estudantes da pós-graduação e $25 \%$ dos estudantes da graduação compuseram a amostra. Cabe destacar, também, que uma outra variável 
atrelada à aprendizagem social, embora emergente, não foi avaliada no estudo, a saber, a relação estudante-mediador, na dimensão de instrução e suporte (KRIZ; HENSE, 2006). Outra limitação refere-se à produção científica em administração que abarque a integração entre estudantes da graduação e da pós-graduação, e, especialmente as que abarquem a relação da integração de níveis diferentes por meio dos jogos de empresa.

Como sugestão para estudos futuros, propõe-se que a avaliação da integração entre graduação e pós-graduação, por meio de jogos de empresas, contemplem a totalidade dos estudantes para que os achados sejam mais consistentes. Sugere-se, ainda, estudos comparados entre amostras que foram submetidas a esse tipo de integração com amostras que não foram submetidas à mesma proposta metodológica. Em outro aspecto, aventa-se correlacionar o método com teorias que expliquem melhor o fenômeno da aprendizagem social e metodologias de ensino-aprendizagem nos âmbitos dos referidos níveis. Indica-se, também, analisar as implicações a longo prazo da integração no que concerne aos efeitos provocados nos estudantes da graduação, quanto à continuidade da carreira acadêmica na pós-graduação, em comparação com estudantes que não foram submetidos à integração.

Outrossim, como a produção técnico-científica produzida no Laboratório de Gestão durante a vivência não foi alvo deste estudo, recomenda-se que os artigos produzidos durante as disciplinas sejam analisados, no que diz respeito aos processos de construção, se colaborativa ou não, bem como, aos processos de aprendizagem. Outros estudos também podem debruçar-se sobre o uso de jogos de empresas enquanto prática docente, uma vez que, a disciplina de Gestão Empresarial Simulada, cursada por estudantes de mestrado e, possivelmente, futuros professores, também aborda as bases teóricas para o uso de jogos de empresa para a educação gerencial. Nesse sentido, a percepção do mestrando acerca do percurso de aprendizagem percorrido pelo estudante da graduação, à luz do Ciclo de Kolb, pode ser investigada.

Por fim, a lacuna entre teoria e prática, especialmente quando se discute pesquisa científica em administração no Brasil, convida à reflexão acerca da premência de capacitação adequada para os profissionais de ges- 
tão, posto que, essa demanda foi pano de fundo para o desenvolvimento da educação em administração no Brasil. Pano de fundo esse, que causa embaraço ao cogitar a possibilidade de que o conhecimento produzido na academia tenha relevância diminuída aos praticantes da arte. No entanto, formar bons profissionais, embora explícita, não é a única função da universidade, mas, a difusão de conhecimentos que possibilitem situar, definir, contextualizar problemas, ao passo que traduz os achados em um exercício crítico e articulado com outros níveis de ensino, com outros pesquisadores, com praticantes e com pesquisados. Portanto, a articulação entre ensino e pesquisa, pressuposto do Laboratório de Gestão, atrelado a níveis de ensino diferentes, pode contribuir para uma relação mais virtuosa entre graduação e pós-graduação (MASCARENHAS; ZAMBALDI; MORAES, 2011; RODRIGUES, 2012; SAUAIA, 2013). 


\section{REFERENNCIAS}

BARDIN, L. Análise de conteúdo. Lisboa: Edições 70, 2013.

BEN-ZVI, T. The efficacy of business simulation games in creating Decision Support Systems: An experimental investigation. Decision Support Systems, v. 49, n. 4, p. 61-69, jan. 2010. DOI: $10.1016 /$ j.dss.2010.01.002.

BERTERO, C. O. A docência numa universidade em mudança. Cadernos EBAPE.BR, v. 5, n. SPE, p. 01-11, 2007. DOI: 10.1590/S1679-39512007000500003.

BRASIL. Ministério da Educação, Coordenação de Aperfeiçoamento de Pessoal de Nível Superior. Plano Nacional de Pós-Graduação - PNPG - 2011-2020. Disponível em: <https: / / www.capes.gov.br/images/stories/download/Livros-PNPG-Volume-I-Mont.pdf > . Acesso em: 25 ago. 2017.

BRASIL. Constituição da República Federativa do Brasil de 1988. [Versão eletrônica]. Brasília: Presidência da República. Disponível em: < http:/ / www.planalto.gov.br/ccivil_03/constituicao/constituicaocompilado.htm>. Acesso em: 25 ago. 2017.

CLOSS, L. Q.; ARAMBURU, J. V.; ANTUNES, E. D. Produção científica sobre o ensino em Administração: uma avaliação envolvendo o enfoque do Paradigma da Complexidade. GESTÃO.Org - Revista Eletrônica de Gestão Organizacional, v. 7, n. 2, p. 150-169, 2009. DOI: $10183 / 107169$

CROOKALL, D. Serious games, debriefing, and simulation/gaming as a discipline. Simulation \& Gaming, v. 41, n. 6, p. 898-920, ago. 2010. doi: 10.1177/1046878110390784.

COOPER, D. R.; SCHINDLER, P. S. Métodos de pesquisa em administração. 10. ed. Porto Alegre: Bookman, 2011.

CURY, C. R. J. Graduação/pós-graduação: a busca de uma relação virtuosa. Educ. Soc. v. 25, n. 88, p. 777-793, out. 2004. DOI: 10.1590/S0101-73302004000300007.

DOLINSKA, A. Bringing farmers into the game. Strengthening farmers' role in the innovation process through a simulation game, a case from Tunisia. Agricultural Systems, v. 157, p. 129-139, 2017. DOI:10.1016/j.agsy.2017.07.002.

FARIA, A. J.; et al. Developments in business gaming: A review of the past 40 years. Simulation \& Gaming, v. 40, n. 4, p. 464-487, dez. 2009. DOI:10.1177/ 1046878108327585.

FERNANDES, J. D.; et al. Modalidades da integração da pós-graduação com a graduação no ensino de enfermagem. Revista Baiana de Enfermagem, v. 29, n. 3, p. 192-200, jul. / set. 2015. DOI: $10.18471 /$ rbe.v29i3.13486.

FISCHER, T. Engenhos e artes no ofício de ensinar: PDCA, Programa Brasileiro. Organizações \& Sociedade, v. 12, n. 35, p. 183-193, 2005.

FLICK, U. Introdução à pesquisa qualitativa. 3. ed. Porto Alegre: Artmed, 2009. 
FREITAS, A.; FISCHER, T. Programa de Capacitação Docente em Administração (PCDA). Cad. EBAPE.BR, Rio de Janeiro, v. 5, n. spe, p. 01-02, jan. 2007. DOI: 10.1590/ S1679-39512007000500002

FREITAS, S. F.; GODOI, C. K. A aprendizagem organizacional sob a perspectiva sócio-cognitiva: contribuições de Lewin, Bandura e Giddens. Revista de Negócios, v. 13, n. 4, p. 40-55, 2008. DOI: 10.7867/1980-4431.2008v13n4p40-55.

FRIEDRICH, H. F.; HRON, A.; HESSE, F. W. A framework for designing and evaluating virtual seminars. European Journal of Education, v. 36, n. 2, p. 157-174, jun. 2001. DOI: $10.1111 / 1467-3435.00057$.

GIL, A. C. Métodos e técnicas de pesquisa social. 6a. ed. São Paulo: Atlas, 2008.

GILMORE, Joanna et al. The relationship between undergraduate research participation and subsequent research performance of early career STEM graduate students. The Journal of Higher Education, v. 86, n. 6, p. 834-863, 2015. DOI: $10.1080 / 00221546.2015 .11777386$.

GODOI, C. K.; FREITAS, S. M. F.; CARVALHO, T. B. Motivação na aprendizagem organizacional: construindo as categorias afetiva, cognitiva e social. Revista de Administração Mackenzie, v. 12, n. 2, p. 30-54. mar./abr. 2011. DOI: http://dx.doi.org/10.1590/S167869712011000200003 .

GOMES, M. Y. F. S. F. Desafios e perspectivas para a integração graduação/pós-graduação em Ciência da Informação: o caso do ICI/UFBA. Perspectivas em Ciência da Informação, v. 17, n. 3, p. 51-66, ago. 2012. DOI: 10.1590/S1413-99362012000300005.

HATHAWAY, R. S.; NAGDA, B. A.; GREGERMAN, S. R. The relationship of undergraduate research participation to graduate and professional education pursuit: an empirical study. Journal of College Student Development, v. 43, n. 5, p. 614, 2002.

HAUGE, J. B. et al. Field assessment of serious games for entrepreneurship in higher education. Journal of Convergence Information Technology, v. 8, n. 13, 174-186, ago. 2013. DOI: 10.1.1.705.7634\&rep $=$ rep $1 \&$ type $=$ pdf

HERNÁNDEZ-LARA, A. B.; PERERA-LLUNA, A.; SERRADELL-LÓPEZ, E. Applying learning analytics to students' interaction in business simulation games: The usefulness of learning analytics to know what students really learn. Computers in Human Behavior, 2018. No prelo. DOI: $10.1016 /$ j.chb.2018.03.001

KEYS, B.; WOLFE, J. The role of management games and simulations in education and research. Journal of Management, v. 16, n. 2, p. 307-336, jun. 1990. DOI: $10.1177 / 014920639001600205$.

KLABBERS, J. H. G. Gaming and simulation: principles of a science of design. Simulation \& Gaming, v. 34, n. 4, p. 569-591, 2003. DOI: $10.1177 / 1046878103258205$.

KLABBERS, J. H. G. On the architecture of game science: A rebuttal. Simulation \& $\mathrm{Ga}$ ming, v. 49, n. 3, p. 207-245, jun., 2018. DOI: 10.1177/1046878118762534. 
KOLB, D. A. Experiential learning: experience as the source of learning and development. 2. ed. New Jersey: Person Education, 2015.

KOLB, A. Y.; KOLB, D. A. Learning styles and learning spaces: Enhancing experiential learning in higher education. Academy of Management Learning \& Education, v. 4, n. 2, p. 193-212, jun. 2005. DOI: 10.5465/ AMLE.2005.17268566.

KRIZ, W. C.; AUCHTER, E. 10 Years of Evaluation Research Into Gaming Simulation for German Entrepreneurship and a New Study on Its Long-Term Effects. Simulation \& Gaming, v. 47, n. 2, p. 179-205, mar. 2016. DOI: 10.1177/1046878116633972.

KRIZ, W. C.; HENSE, J. U. Theory-oriented evaluation for the design of and research in gaming and simulation. Simulation \& Gaming. v 37 n. 2, p. 268-283, jun. 2006. DOI: $10.1177 / 1046878106287950$.

LEFRANÇOIS, G. R. Teorias da aprendizagem: o que o professor disse. São Paulo: Cengage, 2016.

LE PAGE, C. PERROTTON, A. KILT: A modelling approach based on participatory agent-based simulation of stylized socio-ecosystems to stimulate social learning with local stakeholders. Multi-Agent Based Simulation XVIII: International Workshop, MABS, 2017, Revised Selected Papers, São Paulo, Brasil. Anais... São Paulo: Springer, 2018. DOI: 10.1007/978-3-319-71679-4_3.

LODDERS, N. M. P. Teachers learning and innovating together: exploring collective learning and its relationship to individual learning, transformational leadership and team performance in higher vocational education. Twent: Faculty of Behavioural, Management and Social Sciences, 2013. DOI: 10.3990/1.9789036534956

LOPES, M. C. et al. Business games for leadership development: A systematic review. Simulation \& Gaming, v. 44, n. 4, p. 523-543, 2013. DOI: 10.1177/1046878112471509

LOURENCO, C. D. S; LIMA, M. C.; NARCISO, E. R. P. Formação pedagógica no ensino superior: o que diz a legislação e a literatura em educação e administração? Avaliação (Campinas), v. 21, n. 3, p. 691-718, nov., 2016. DOI: 10.1590/S1414-40772016000300003.

MASCARENHAS, A. O.; ZAMBALDI, F.; MORAES, E. A. Rigor, relevância e desafios da academia em administração: tensões entre pesquisa e formação profissional. Rev. adm. empres., São Paulo, v. 51, n. 3, p. 265-279, mai/jun. 2011. DOI: http:/ / dx.doi. org/10.1590/S0034-75902011000300007

MARAFON, M. R. C. Articulação pós-graduação e graduação: desafio para a educação superior. 2001. 208f. Tese (Doutorado em Educação). Universidade Estadual de Campinas (UNICAMP), Campinas. 2001. Disponível em: < repositorio.unicamp.br/jspui/handle/ REPOSIP/251889>. Acesso em: 22 set. 2018.

MAYER, I.; WARMELINK, H.; BEKEBREDE, G. Learning in a game-based virtual environment: a comparative evaluation in higher education. European Journal of Engineering Education, v. 38, n. 1, p. 85-106, 2013. DOI: 10.1080/03043797.2012.742872 
MOTTA, G. S. et al. O perfil da pesquisa acadêmica sobre jogos de empresas entre 2001 e 2010. In: ENCONTRO DA ANPAD-EnANPAD, v. 35, 2011, Rio de Janeiro. Anais... Rio de Janeiro: ANPAD, 2011. Disponível em: <http:/ /www.anpad.org.br/admin/pdf/ EPQ1318.pdf>. Acesso em: 23 abr. 2017.

MOTTA, G. S.; MELO, D. R. A.; PAIXÃO, R. B. O jogo de empresas no processo de aprendizagem em administração: o discurso coletivo de alunos. RAC-Revista de Administração Contemporânea, v. 16, n. 3, p. 342-360, mai./jun. 2012. DOI: 10.1590/S141565552012000300002 .

MRTVI, V. O. et al. Jogos de empresas: abordagens ao fenômeno, perspectivas teóricas e metodológicas. Revista de Administração Contemporânea, v. 21, n. 1, p. 19-40, jan./ fev. 2017. DOI: $10.1590 / 1982-7849$ rac2017150212.

NICOLINI, A. Qual será o futuro das fábricas de administradores? Revista de Administração de Empresas, v. 43, n. 2, p. 44-54, 2003. DOI: 10.1590/S0034-75902003000200003.

NUNES, E. Desafio estratégico da política pública: o ensino superior brasileiro. Rev. Adm. Pública, Rio de Janeiro, v. 41, n. spe, p. 103-147, 2007. DOI: 10.1590/S003476122007000700008.

OLIVEIRA, M. A. Implantando o Laboratório de Gestão: um programa integrado de educação gerencial e pesquisa em administração. 2009. 293f. Tese (Doutorado em Administração) - Faculdade de Economia, Administração e Contabilidade, da Universidade de São Paulo, São Paulo, 2009. DOI: 10.11606/T.12.2009.tde-18122009-094527

OLIVEIRA, M. A. Laboratório de Gestão Simulada II. Volta Redonda: In mimeo, 2017.

OLIVEIRA, M. A; SAUAIA, A. C. A. Impressão docente para aprendizagem vivencial: um estudo dos benefícios dos jogos de empresas. Administração: Ensino e Pesquisa, Rio de Janeiro, v. 12, n. 3, p. 355-391, jul./ ago./set. 2011. DOI: 10.13058/raep.2011.v12n3.159

OLIVEIRA, M.A. et al. Relação entre conhecimento e desempenho gerencial: análise do aprendizado dos participantes de um jogo de empresas. In: ENCONTRO DA ANPADEnANPAD, v. 34, 2010, Rio de Janeiro. Anais... Rio de Janeiro, 2010. Disponível em: <http://www.anpad.org.br/admin/pdf/epq977.pdf>. Acesso em: 23 abr. 2017.

PINTO, V. R. R.; MOTTER JUNIOR, M. D. Uma abordagem histórica sobre o ensino da Administração no Brasil. Revista Pensamento Contemporâneo em Administração, v. 6, n. 4, p. 1-28, 2012. DOI: $10.12712 /$ rpca.v6i4.250

RICHARDSON, R. J. Pesquisa Social: métodos e técnicas. 3a. ed. São Paulo: Atlas, 2012.

RODRIGUES, M. E. F. A articulação ensino-pesquisa como indicador de inovação na formação do profissional da informação. Liinc em Revista, Rio de Janeiro, v. 7, n. 1, p. 214230, mar. 2011. DOI: 10.18617/liinc.v7i1.410.

RODRIGUES, M. E. F. A pesquisa no ensino de graduação e a articulação com a pós-graduação na ciência da informação: reflexões e proposições. PontodeAcesso, v. 6, n. 2, p. 03-20, ago. 2012. DOI: 10.9771/1981-6766rpa.v6i2.6099. 
OLIVEIRA

ROSAS, A. R.; SAUAIA, A. C. A. Jogos de empresas na educação superior no Brasil: perspectivas para 2010. Enfoque Reflexão Contábil, v. 25, n. 3, p. 72-85, set./ dez. 2006. DOI: 10.4025 / enfoque.v25i3.3489.

SAUAIA, A. C. A. Conhecimento versus desempenho das organizações: um estudo empírico com jogos de empresas. REAd-Revista Eletrônica de Administração, v. 12, n. 1, p. 1-18, jan./ fev. 2006.

SAUAIA, A. C. A. Laboratório de gestão: simulador organizacional, jogo de empresas e pesquisa aplicada. 3. ed. Barueri: Manole, 2013.

SILVA, E. L.; MENEZES, E. M. Metodologia da pesquisa e elaboração de dissertação. 4a. ed. Florianópolis: UFSC, 2005.

SILVA, S. S. Laboratório de gestão online: análise da contribuição da aprendizagem vivencial. 2015. 210 f. Dissertação (Mestrado Profissional em Administração) - Instituto de Ciências Humanas e Sociais, Universidade Federal Fluminense, Volta Redonda, 2015. Disponível em: < http:/ /ppga.sites.uff.br/wp-content/uploads/sites/117/2017/07/Disserta\%C3\%A7\%C3\%A3o-Sheila-Serafim-da-Silva-1.pdf>. Acesso em: 22 set. 2018.

SILVA, S. S.; OLIVEIRA, M. A.; MOTTA, G. S. Jogos de empresas e método do caso: contribuições ao processo de ensino e aprendizagem em administração. Administração: Ensino e Pesquisa, v. 14, n. 4, p. 677-705, 2013. DOI: 10.13058/raep.2013.v14n4.52.

STATION, A. J; JOHNSON, E. J; BORODZICZ, E. P. Education validity of business gaming: a research methodology framework. Simulation \& Gaming, v. 41, n. 5, p. 705-723, abr. 2010. DOI: $10.1177 / 1046878109353467$.

VALADÃO JÚNIOR, V. M.; RODRIGUES, H. G. Competências na pós-graduação: o olhar dos egressos. Administração: Ensino e Pesquisa, v. 13, n. 2, p. 325-354, 2012. DOI: 10.13058/raep.2012.v13n2.94.

VERGARA, S.C. Projetos e relatórios de pesquisa em administração. 10a. ed. São Paulo: Atlas, 2009. 


\section{DADOS DOS AUTORES}

\section{HUMBERTO REIS DOS SANTOS-SOUZA humberto.souza@ifrj.edu.br}

Mestrando em Administração pela UFF

Instituição de vinculação: Instituto Federal de Educação, Ciência e Tecnologia do Rio de Janeiro - Campus Resende

Resende/RJ - Brasil

Áreas de interesse em pesquisa: Ensino e Pesquisa em Administração, Empreendedorismo.

Av. Prefeito Botafogo S/N Comercial Resende/RJ 27541-030

\section{MURILO ALVARENGA OLIVEIRA malvarenga@id.uff.br}

Doutor em Administração pela USP

Instituição de vinculação: Universidade Federal Fluminense - Departamento de Administração e Adm. Pública (UFF/ICHS)

Volta Redonda/RJ - Brasil

Áreas de interesse em pesquisa: Jogos de Empresas, Simulações Organizacionais, Gestão de Projetos, Processo Decisório e Capacidades de Inovação. 